\title{
Vibration Analysis of a Common Rail Diesel Engine using Biodiesel: A Case Study
}

\author{
G. D. Chaitidis ${ }^{1, *}$, T. S. Karakatsanis ${ }^{1}$, V. Kanakaris ${ }^{1, *}$, K. M. Papachastas ${ }^{2}$ and I. Ch. Tsiafis ${ }^{2}$ \\ ${ }^{1}$ Department of Production \& management Engineer, Democritus University of Thrace \\ ${ }^{2}$ Department of Mechanical Engineer, Aristotle University of Thessaloniki
}

Received 8 April 2019; Accepted 10 September 2019

\begin{abstract}
Biodiesel is a renewable fuel that manufactured from vegetable oils and fat tissues. Biodiesel is mixed with diesel fuel and then is used in combustion engines. The main merit of biodiesel is its less pollution in comparison to pure diesel fuels. A significant property of diesel fuels during the combustion process is high noise and vibration. Worldwide many researchers worked on vibration of biodiesel and its blends with diesel. Consequently, in this study, evaluation of vibration was performed for biodiesel blends of the proportions ranged from $20 \%$ soybean oil to $80 \%$. For this, a common rail diesel engine of capacity is $1248 \mathrm{cc}$, was used. It has found that most of vibration accelerations were rising between 1800 and $2000 \mathrm{rpm}$. Results showed that the total vibration values are reduced significantly after servicing the engine by $12 \%$. Statistical analysis of data showed that the vibration was lowest for B40 and B20. The results showed that the vibration of the diesel (D100) is less than biodiesel (B100). Finally, at different engine speeds, vibration was always consistent with power-torque curve.
\end{abstract}

Keywords: Biodiesel, Diesel, Vibration, Common Rail, Engine

\section{Introduction}

Generally, biodiesel consists of vegetable oils, or waste edible oils. For the experiment reasons biodiesel is blended to $20 \%$ with petroleum diesel (B20). Pure biodiesel includes approximately $10 \%$ oxygen by weight [1][2] . In combustion engines, in case a quantity of oxygen occurred in the biodiesel it causes then reduction of emissions such as hydrocarbons, carbon dioxide, and more [3][4]. Whereas of the globally growing energy request and environmental deliberations, many countries have conformed some relatives strategies [4][5]. Particularly, in 2017 in European Union devoted a $12 \%$ share of the motor fuel. On the other hand, the US Energy Department in 2015 decided that more than 50\% of diesel fuel usage could be superseded by biodiesel. Until now in France $12 \%$ of biodiesel is used in mixed with pure diesel while in the US and Brazil is used only the $2 \%$. The predictions for the year 2021 show that the percentage of biodiesel that will be used in mixed with pure diesel will be rise to $10 \%$ [3][4][5].

The effects of vibrations of diesel and gas internal combustion engines have been examined in different perspectives. The process of fuel combustion inside the engine could have immediate effects on users. Noise and vibrations from diesel engine noise can produce detrimental on the ears and the whole body. Most of all the abovementioned findings noticed in the engines with high fuel pressure combustion and compression ratio $[6][7][8][9][10][11]$. There were many experiments that have been contacted on cylinder blocks in diesel and gas engine in order to be examined the vibration effect. The diesel fuel

*-mail address: vkanak@teiemt.gr

ISSN: 1791-2377 @ 2019 School of Science, IHU. All rights reserved.

doi:10.25103/jestr.125.19 quantity together with time and number injection, are greatly affected the vibration on block of cylinder [12]. The results of a research, that conducted in order to examine the vibration of the engine during the effect of cooling water temperature, indicated that reducing cooling water temperature it rises the vibration frequencies between 500 and $2000 \mathrm{~Hz}$ and consequently, water temperature should be managed. [13]. Another important coefficient is the piston slap of the engine cylinder block vibration. Problems in valves of the diesel engines is also a factor that rises the vibrations. These types of faults can be recognized using Neural Network Probabilistic (NNP) [14][15][16]. Ettefagh et al. [17] examined the vibrations caused during the ignition process by analysing the phenomena in the cylinder block and created a model called Auto Regressive Moving Average (ARMA). The results indicated that the suggested method is able to recognize vibrations easing only by using a low cost sampling rate equipment [17].

Guzzomi et al. [12] studied the torsional vibrations in engine parts and provided some unusual event during the vibrations, which happened because the reciprocating mechanism geometry. Except, that system inaction is varied with crankshaft rotation; the results also indicated that the generated vibration is affected by the friction between the cylinder and piston. [18]. Piston slap is the main reason that causes the vibration of the impact during the transient response of cylinder [19]. Chen et al. also studied the case of piston slap in the reciprocating engine using Probabilistic Neural Network (PNN) in order to identify the cylinder fault Error! Reference source not found. A special dynamic simulation software was used in order to test and simulate piston slap faults in a variety of speeds/loads. Moreover, there was a validation process using a number of assessments regarding the simulation models. The Probabilistic Neural Network (PNN) method that presented trains the networks on 
simulated data can effectively discover piston slap faults in actual tests and recognize the location and tartness of the errors Error! Reference source not found.

$\mathrm{Ra}$ et. al. conducted a research that focus on noise produced by engine vibration due to hitting internal the cylinder, and noise data were measured in a small single cylinder Direct Injection (DI) diesel engine [20]. The researchers took measurements from the pressure inside the cylinder, the fuel line pressure and acceleration signals and analyzed them at the time and frequency domains and in different engine angular velocities. The results from the comparison with existing data for multi-cylinder diesel engine showed that the measurements in average was much higher than the available values because its lusty construction. Taghizadeh [22][23] made a research at the effect of vibration on the operator of a power tiller with diesel engine (Mitsubishi, $7.7 \mathrm{hp}-2400 \mathrm{rpm}$ ). The measurements taken at different situations such as steady state, walking, plowing and transportation states. The findings showed that during the increasing speed of the engine, the values of acceleration were also rising along with the 3 axes. Moreover the main frequency of vibration in each locations and axes compensates the number of the piston stroke or number of rotations in engine $[18,19]$. The literature reviews, show that there are not many researches on the diesel engine vibration using biodiesel or the blends of diesel-biodiesel fuels. Therefore, the main objective of this research was to detect / examine vibrations are causing by fuel blends are different from pure diesel ones and simultaneously to identify the fuel blends with the minimal and maximal vibrations to be considered by manufactures of common rail diesel engines for improving their engines adopted and avoided respectively by users.

\section{System Overview}

\subsection{Diesel Engine Specifications}

The engine that used in the experiment is a 1248JTD engine. Its capacity is $1248 \mathrm{cc}$, it has 16 valves and its year of manufacture is 2006. The engine designed for front-wheel drive and was used by Fiat. The model name of the engine originated from the letters U (Unijet) T (Turbo) D (Diesel). Table 1 shows the features of the engine. The engine used in the experiment delivers maximum power at 4000 revolutions per minute (rpm) and the minimum number of revolutions is $800 \mathrm{rpm}$. The operating revolutions performed on the experiment were 850, 1150 and 2000. The main moving components of engine are pistons, connecting rods and crankshafts. Vibration in reciprocating engines caused by the changes in gas pressure inside the cylinder and alternating inertia forces concentrated on different engine parts.

Table 1. Engine Specifications

\begin{tabular}{l|ll}
\hline \multicolumn{3}{c}{ Engine Specifications } \\
\hline Engine manufacturer & Fiat JTD/Multijet-series & \\
Engine type & Diesel & \\
Fuel type & Diesel fuel & \\
Fuel system & Common rail & \\
Charge system & Turbocharger & \\
Valves per cylinder & 4 & \\
Additional features & Variable geometry turbo; \\
& intercooler & \\
Emission standard & Euro 4 & \\
Cylinders alignment & Line 4 & \\
Horsepower net & $51.5 \mathrm{~kW} / 70 \mathrm{PS} \mathrm{/} \mathrm{69} \mathrm{hp} \mathrm{(ECE)}$
\end{tabular}

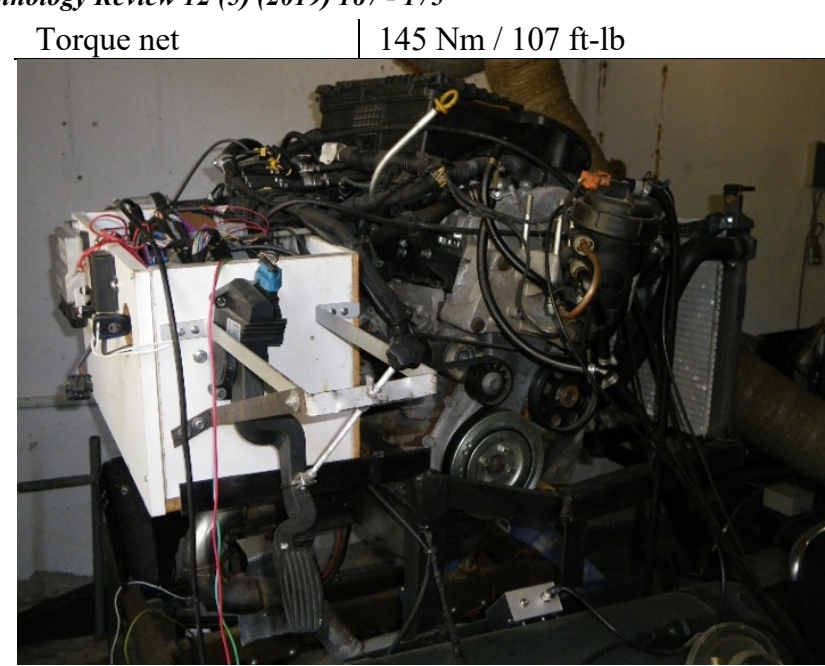

Fig. 1. Diesel Engine Experiment Conducted

\section{2 Biodiesel Proposition}

For the needs of the experiment, seven different types of diesel oil and soybean oil blends with different percentages were set up in the Machine Tools and Forming Engineering Laboratory. The proportions ranged from $20 \%$ soybean oil to $80 \%$. The pure diesel occupied the rest of the mix. Mixtures will be symbolized by their percentage of soybean oil with the $\mathrm{BXX}$ symbol. Where XX is the percentage of soybean oil. Thus, the molded blends are B20, B40, B60, B80.

In this study, four fuel blends (FB) were prepared and used. These blends were, B20, B40, B60, B80, pure biodiesel (B100). Biodiesel used in this research was produced in laboratory of chemistry Democritus University of Thrace (DUTH). In this center, biodiesel is produced from vegetable oils soybean given by ASTM D 6751 \& EN 14214 methods [24].

Table 2. Fuel Ratios

\begin{tabular}{c|c|c}
\hline Type & Diesel (\%) & Biodiesel (Soybean Oil) (\%) \\
\hline B20 & 80 & 20 \\
B40 & 60 & 40 \\
B60 & 40 & 60 \\
B80 & 20 & 80 \\
\hline
\end{tabular}

\subsection{Sensor Specification}

Vibration sensor VSA001 was used to measure vibration. The sensor is characterized by a sensitivity of $0.2(\mathrm{mg} / \sqrt{\mathrm{Hz}})$ and can measure in a frequency range of $0-6000 \mathrm{~Hz}$. The dynamic range of oscillation measurement is $50 \mathrm{~g}( \pm 25 \mathrm{~g})$. The sensor received analog signals, which were transformed into a digital via a suitable converter and stored on a computer. The accelerometer uses the principle of operation by varying the capacity of the capacitor.

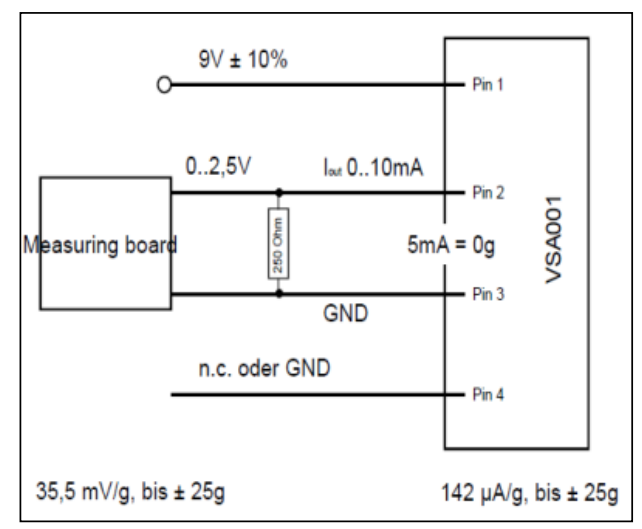




\section{G. D. Chaitidis, T. S. Karakatsanis, V. Kanakaris, K. M. Papachastas and I. Ch. Tsiafis/}

Journal of Engineering Science and Technology Review 12 (5) (2019) 167 - 175

Fig. 2. Accelerometer connection on engine

\section{Method \& Measurements}

Current measurements were made with different fuel mixtures at different speeds. As a result of the measurements made, results were obtained on the acceleration value as a function of time. Through the Fourier transform, the signal was converted from the time domain into the frequency domain to draw conclusions about the rolling relationship engine by correlating the acceleration to the frequency.

Fourier Transform is one of the methods by which a signal is analyzed that tends to be not completely periodic and particularly when the period tends to infinity. The term Fourier Transform refers to a mathematical process that separates a function into a sum of individual infinite periodic sinusoidal functions. The result of this process is a new function with a different definition domain known as Fourier Transform. Through this conversion, it is understood whether each elemental halite is involved in the formation of the original function. The equation describing the Fourier transform of a random function $\mathrm{f}(\mathrm{t})$ is:

$F(\omega)=\int f(t) e^{-j \omega t} d t$

3.1 Analysis of measurements through Fourier Transform Significant Fourier Transform (DFT) is used in signal analysis such as those studied in this experiment. The Discrete Fourier Transform is one of the most basic tools in digital signal processing. It is specialized in analysis:

- Discrete real-time functions of finite length.

- Distinct real functions of fixed periodicity.

- Distinct complex finite-length functions.

- Distinct complex functions of specified periodicity.

To facilitate calculations, Fast Fourier Transform (FFT) has been used through the MATLAB software in order to convert signals from time to frequency spectrum.

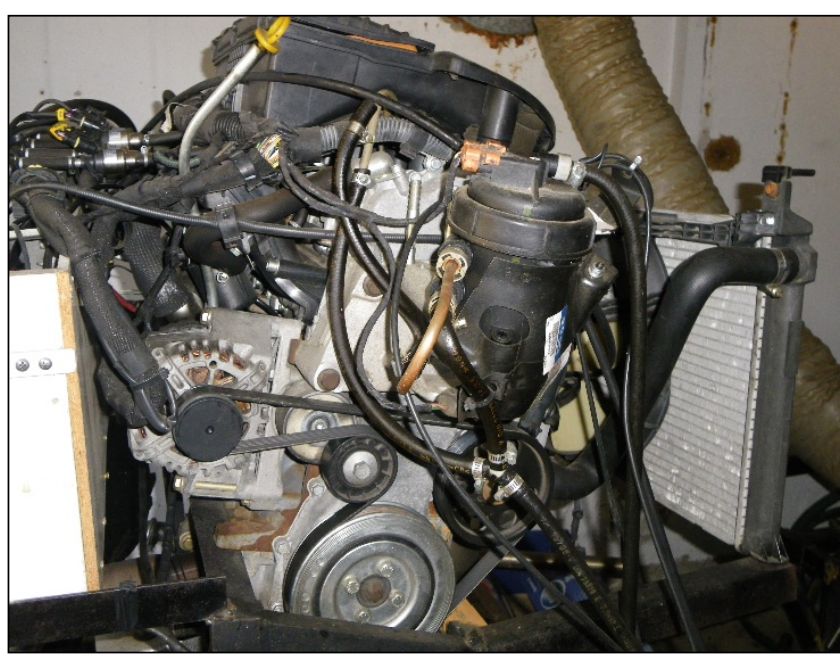

Fig. 3. View of the engine of the experimental device

\section{Results}

The following results that presented are practically the result of the transformation of the signals as they occurred in relation to time and after being converted by FFT into functions that vary with frequency. At this point, it was also necessary to quote the results of the generated noise in order to examine the effect of the user comfort.

In the case of time variation, conclusions can be drawn about the time distance between the phase where the piston will successively reach the upper dead center. In research conducted by Taghizadeh et al (2012) [23] in a corresponding diagram (Figure 5) the times of the upper dead-point of a 6cylinder engine are visible and the time difference is in the order of $0.1 \mathrm{sec}$. In the engine tested in the laboratory the measurement is not filtered and it is more difficult to locate the successive upper points of the measurement and can be approximated as it appears to be present at $0,610^{-4} \mathrm{sec}$ and at $1,610^{-4} \mathrm{sec}$ respectively, then to $2,410^{-4} \mathrm{sec}$ (Figure 4). The difference in time is due to the both different operating speeds and the different engine characteristics (In the experiment of Taghizadeh et al (2012), the engine is bigger than in our research).

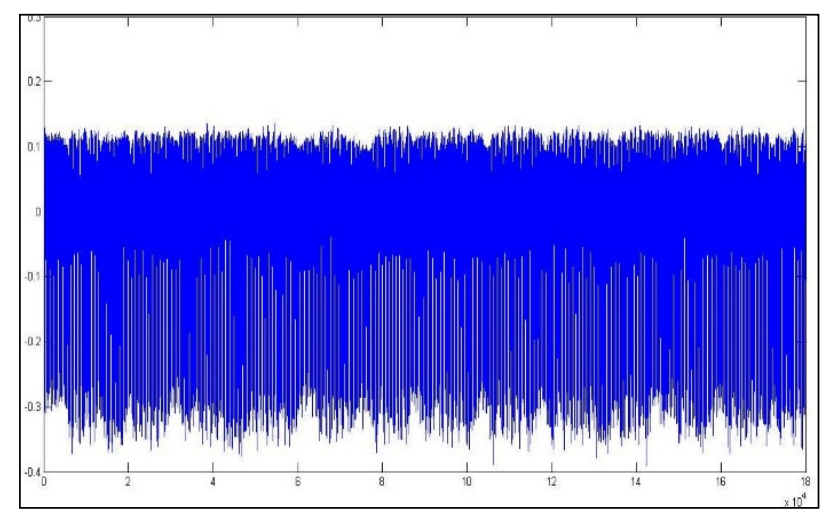

Fig. 4. Time change of acceleration using fuel B20 at $850 \mathrm{rpm}$.

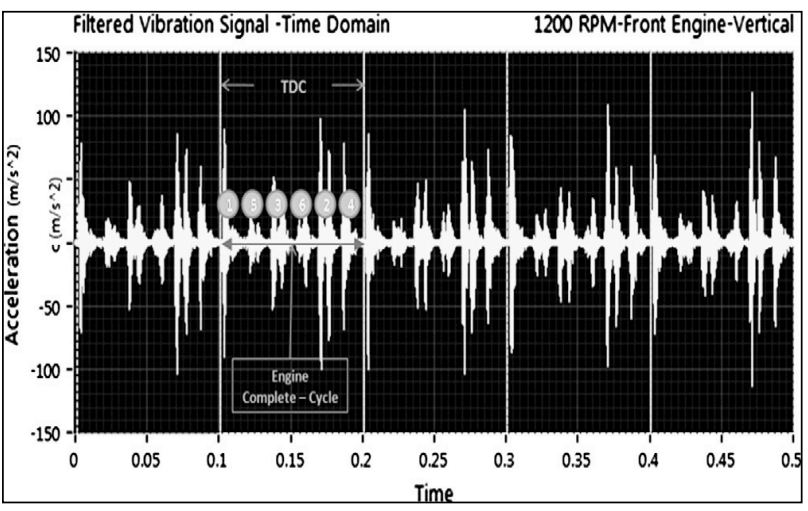

Fig. 5. Time shift of acceleration using B20 at $1200 \mathrm{rpm}$ - Taghizadeh et al (2012)

The outcome of figure 6 comes from the transition through the Fourier transformation into the frequency. This figure shows the local magnitudes of the oscillation range value for different frequencies. Peaks display the highest values at low frequencies and lower at the highest. Particularly it shows $0.013 \mathrm{~g}$ at $50 \mathrm{~Hz}, 0.00375 \mathrm{~g}$ at $60 \mathrm{~Hz}$ and $0.0092 \mathrm{~g}$ at $75 \mathrm{~Hz}$. At $1000 \mathrm{~Hz}$ and $2000 \mathrm{~Hz}$ it again shows two maximums of about $0.0017 \mathrm{~g}$ and $0.0015 \mathrm{~g}$ respectively. This is normal as during the start of the engine the pressure is increased to overheat the fuel mixture. At the other peak values, obviously other diesel cycle processes occur and are accompanied by intense movement of the mechanical parts (piston hit, etc.)At the other peak values, obviously other diesel cycle processes occur and are accompanied by intense movement of the mechanical parts (piston hit, etc.) 
G. D. Chaitidis, T. S. Karakatsanis, V. Kanakaris, K. M. Papachastas and I. Ch. Tsiafis/

Journal of Engineering Science and Technology Review 12 (5) (2019) 167 - 175

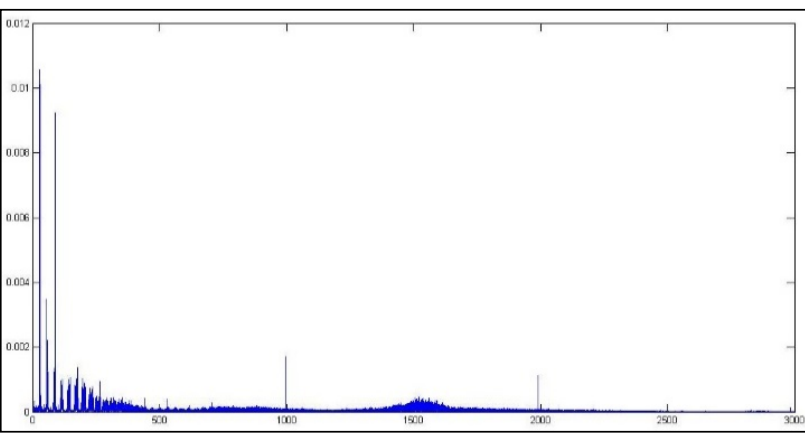

Fig. 6. Signal variation of accelerating action versus frequency using the FFT at $850 \mathrm{rpm}$

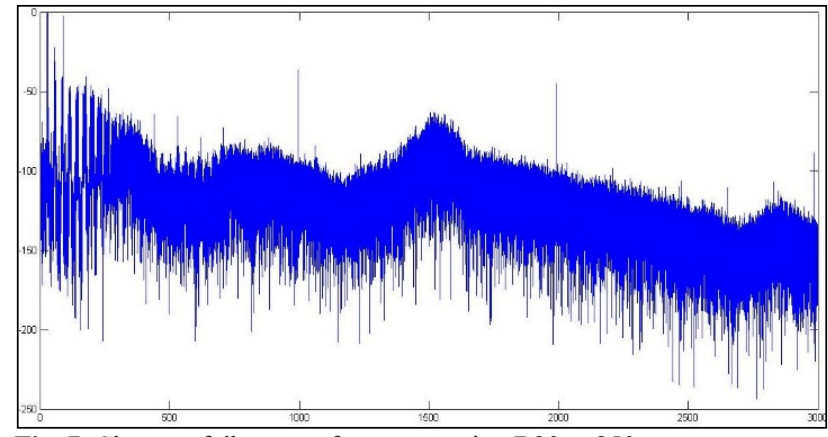

Fig. 7. Change of db versus frequency using B20 at $850 \mathrm{rpm}$

Figure 7 shows that the noise is increased in the early stages of the engine start and gradually decreases with some local peaks at $1000 \mathrm{~Hz}$ and $2000 \mathrm{~Hz}$. Noise levels are also reasonable to limit to higher frequencies as long as engine operation is smooth.

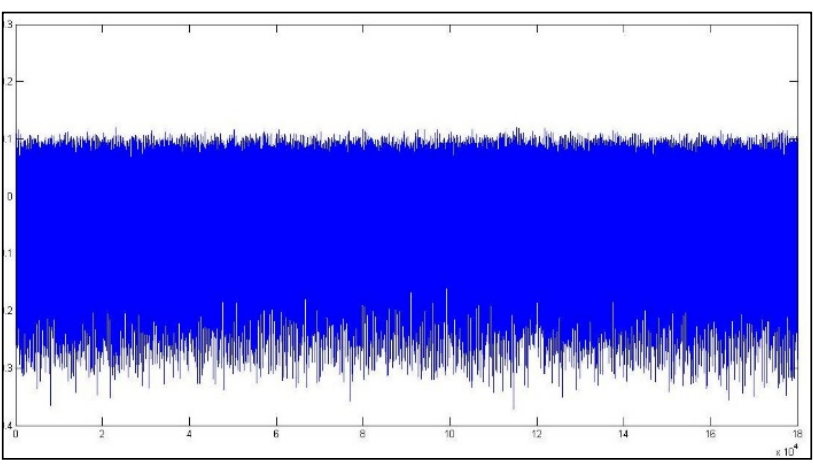

Fig. 8. Time shift of acceleration using fuel B20 at $1150 \mathrm{rpm}$

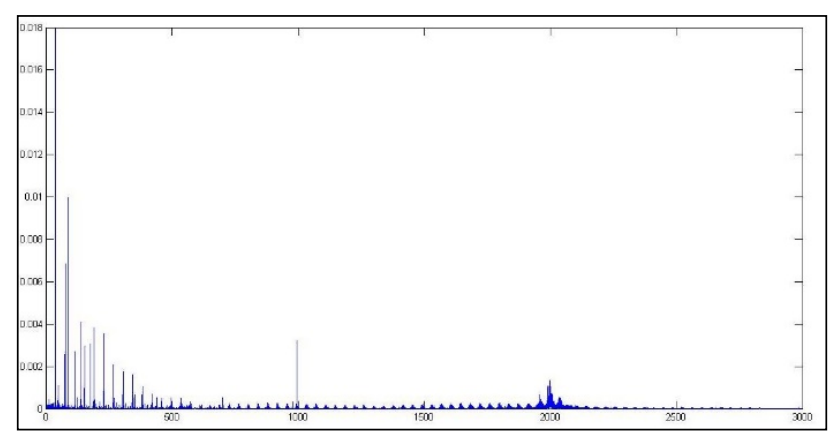

Fig. 9. Signal variation of accelerating action versus frequency using the FFT at $1150 \mathrm{rpm}$

Figure 14 to 22 shows that the noise is increased in the early stages of the engine start and gradually decreases with some local peaks at $1000 \mathrm{~Hz}$ and $2000 \mathrm{~Hz}$. Noise levels are also reasonable to limit to higher frequencies as long as engine operation is smooth. Also those figures shows that B40 mixture provides more noise and engine vibrations compared to B20 and B60 blends. The frequency spectrum diagram shows that the accelerator action value displays a higher maximum at low frequencies (i.e., at ignition), respectively, the maximums at the higher frequencies have higher values than those displayed at $850 \mathrm{rpm}$. Specifically at $50 \mathrm{~Hz}$ its value reaches $0.018 \mathrm{~g}$ while at $0.75 \mathrm{~Hz}$ is $0.01 \mathrm{~g}$. At $1000 \mathrm{~Hz}$ its value reaches 0.00350 . These values are higher because higher power is required for the engine to operate at these rpm, requiring higher pressure at the start and higher upward oscillating acceleration. Noise levels are also higher and even more definite.

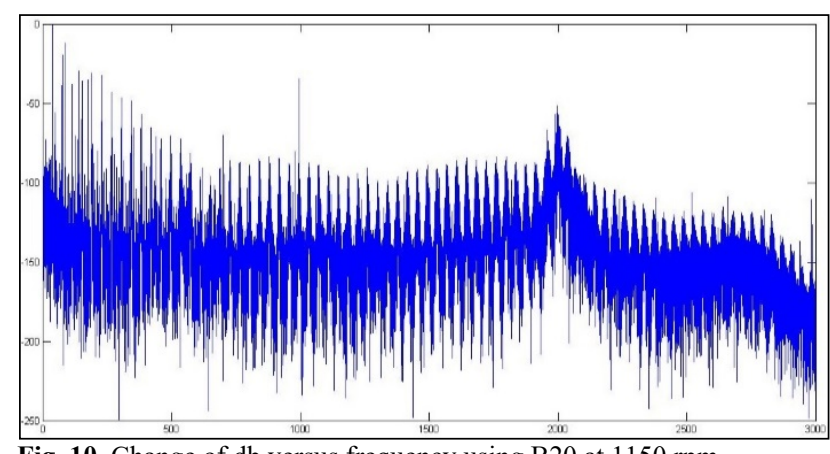

Fig. 10. Change of db versus frequency using B20 at $1150 \mathrm{rpm}$

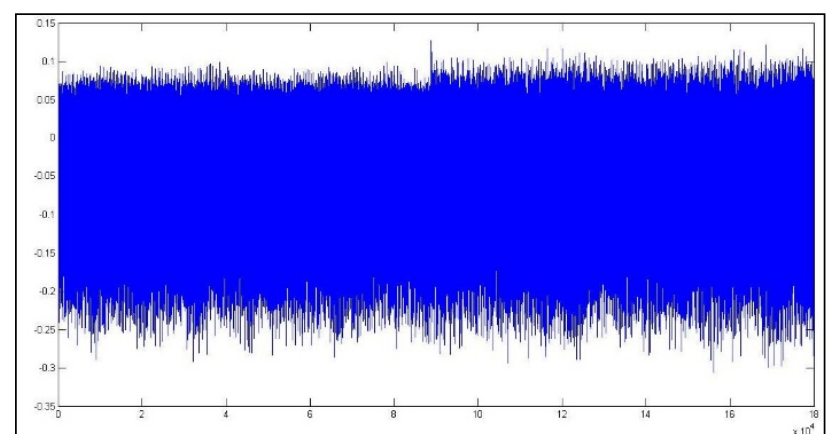

Fig. 11. Time shift of acceleration using fuel B20 at $2000 \mathrm{rpm}$

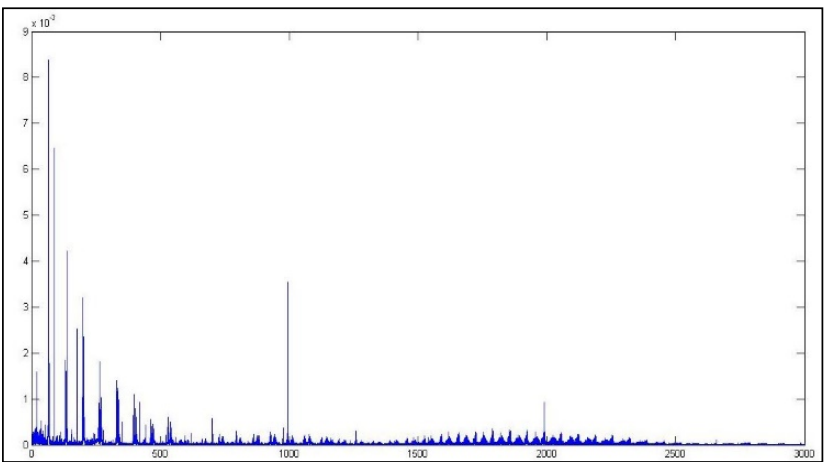

Fig. 12. Signal variation of accelerating action versus frequency using the FFT at $2000 \mathrm{rpm}$

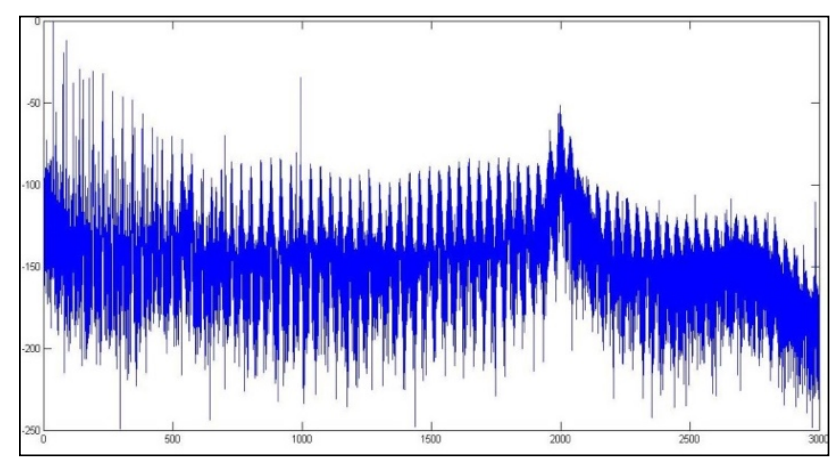

Fig. 13. Change of $d b$ versus frequency using $B 20$ at $2000 \mathrm{rpm}$ 
G. D. Chaitidis, T. S. Karakatsanis, V. Kanakaris, K. M. Papachastas and I. Ch. Tsiafis/

Journal of Engineering Science and Technology Review 12 (5) (2019) 167 - 175

noise level. In conclusion, the increase in the biodiesel percentage has improved the behavior of the motor at stressoscillation level, regardless of performance levels. The 1150

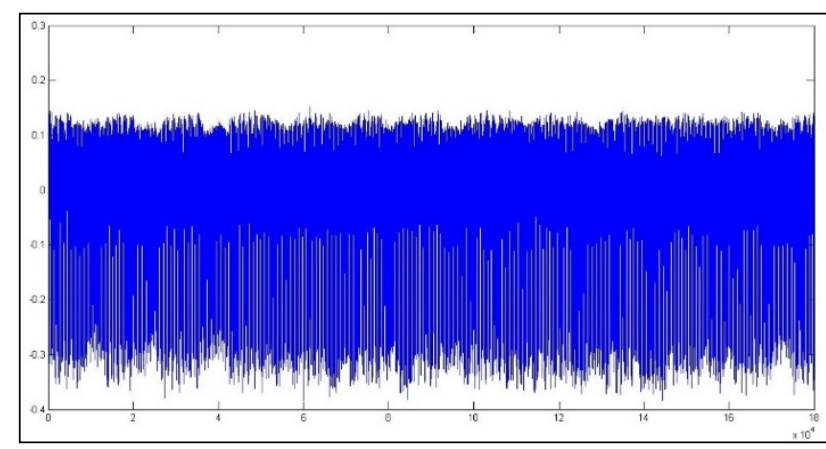

Fig. 14. Time change of acceleration using fuel $\mathrm{B} 40$ at $850 \mathrm{rpm}$.

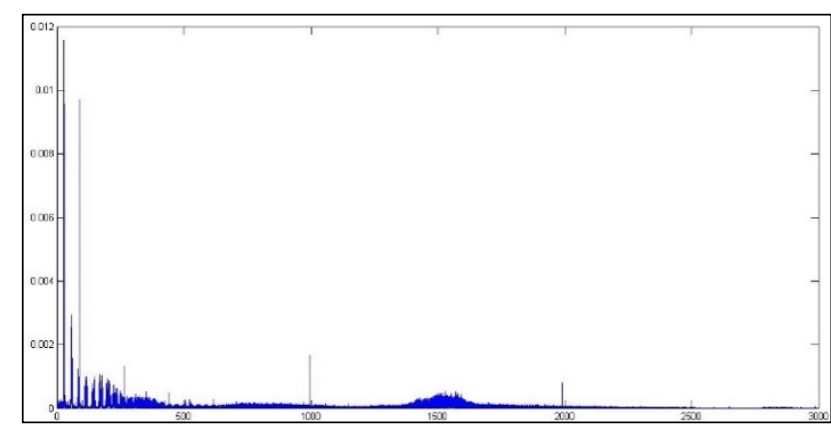

Fig. 15. Signal variation of accelerating action versus frequency using the FFT at $850 \mathrm{rpm}$

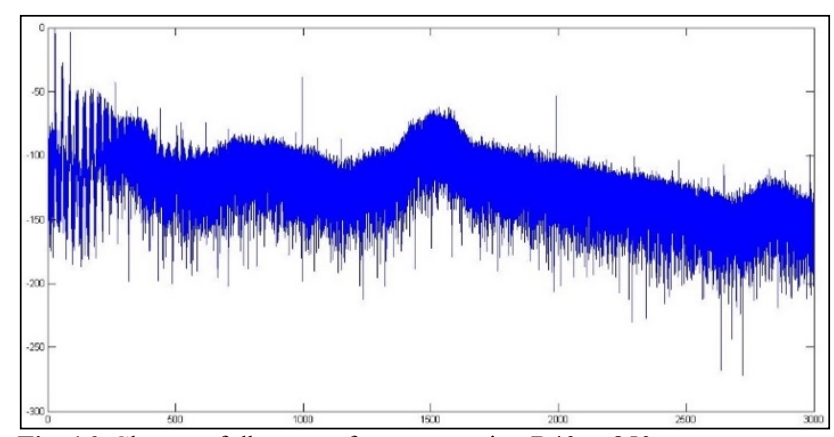

Fig. 16. Change of db versus frequency using B40 at $850 \mathrm{rpm}$

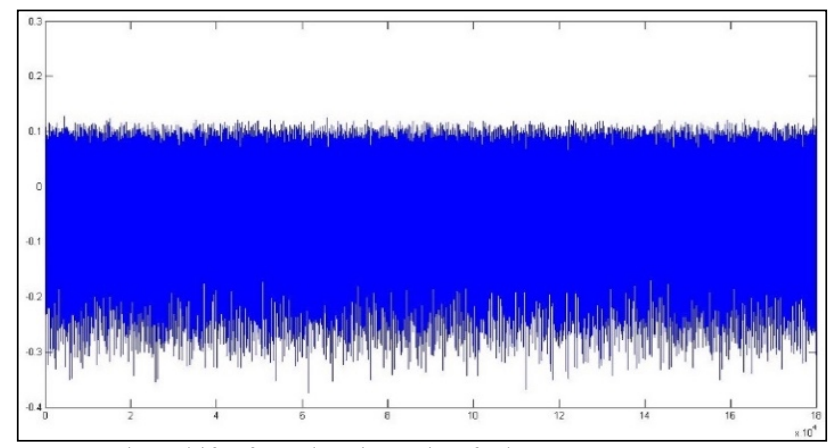

Fig. 17. Time shift of acceleration using fuel B40 at $1150 \mathrm{rpm}$

The behavior of the intermediate mixture where the biodiesel content of the fuel is $60 \%$ will be presented. The figures in 23-31 show the behavior of the engine at $850 \mathrm{rpm}$ and a similar presentation for the 1150 and 2000 turns will accordingly be made. The acceleration value at $50 \mathrm{~Hz}$ has dropped to $0.00108 \mathrm{~g}$ versus $0.0013 \mathrm{~g}$ relative to the $20 \%$ biofuel content. Reduced acceleration values are also observed at higher frequencies, for example at $75 \mathrm{~Hz}$ where it is about $0.01 \mathrm{~g}$ (similar to B20). Also at $1000 \mathrm{~Hz}$ it displays a slightly lower value. There is also limited variation in the and 2000 turns are respectively shown for the B60 fuel in Figures 26-31.

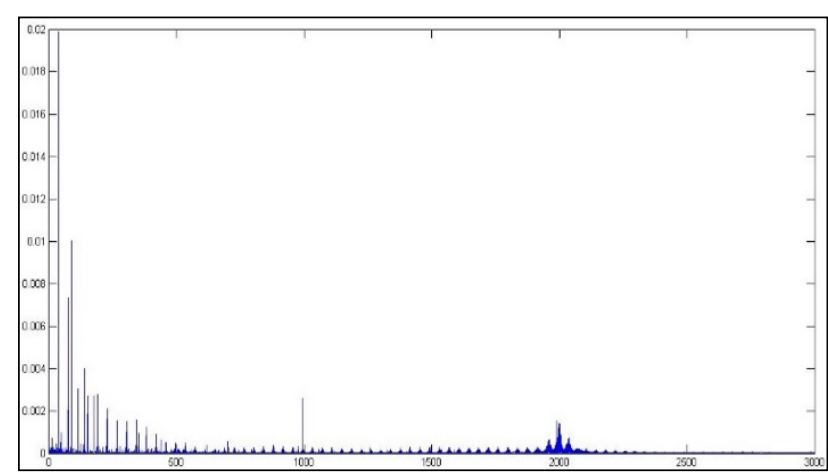

Fig. 18. Signal variation of accelerating action versus frequency using the FFT at $1150 \mathrm{rpm}$

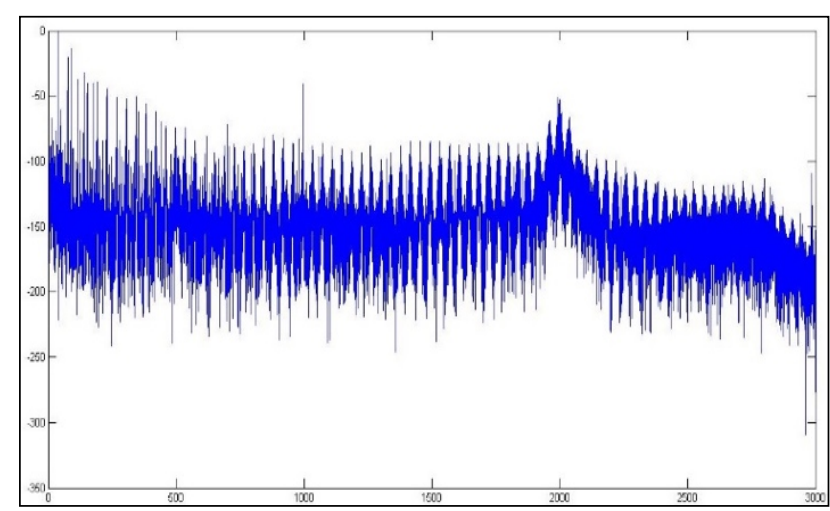

Fig. 19. Change of db versus frequency using B40 at $1150 \mathrm{rpm}$

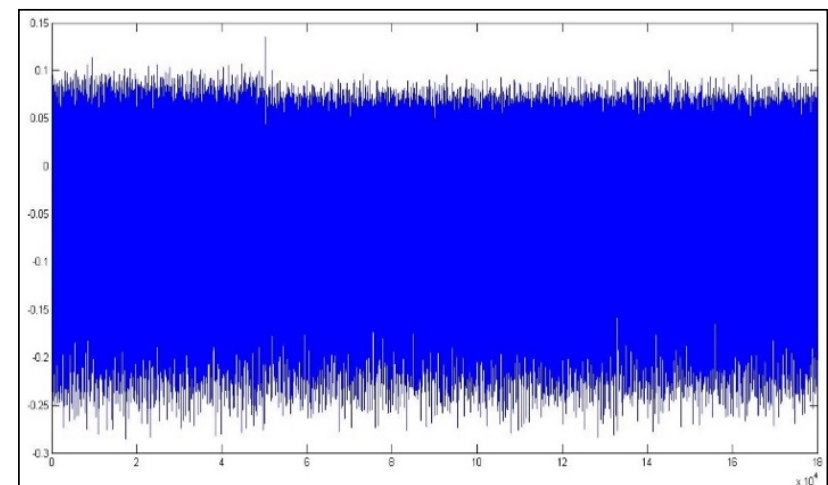

Fig. 20. Time shift of acceleration using fuel B40 at $2000 \mathrm{rpm}$

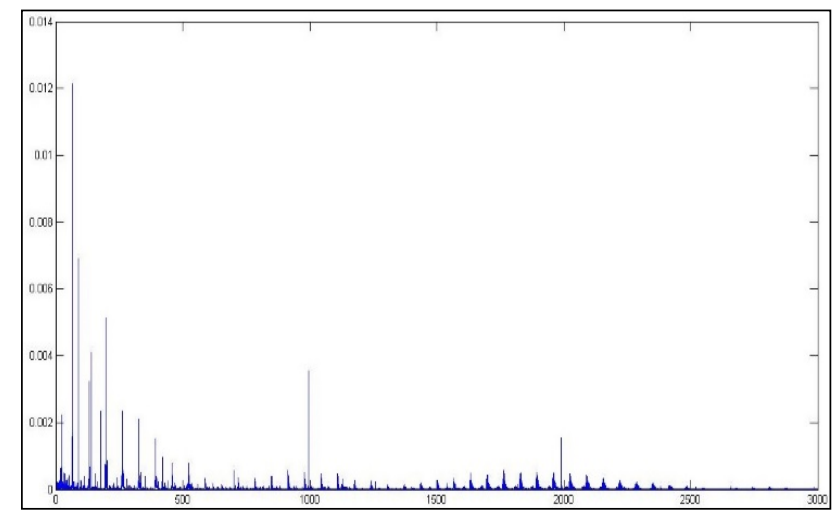

Fig. 21. Signal variation of accelerating action versus frequency using the FFT at $2000 \mathrm{rpm}$ 
G. D. Chaitidis, T. S. Karakatsanis, V. Kanakaris, K. M. Papachastas and I. Ch. Tsiafis/

Journal of Engineering Science and Technology Review 12 (5) (2019) 167 - 175

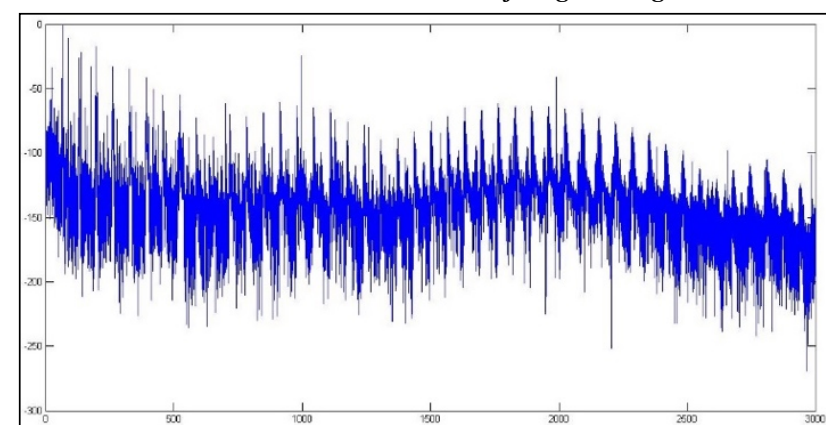

Fig. 22. Change of db versus frequency using B40 at $2000 \mathrm{rpm}$

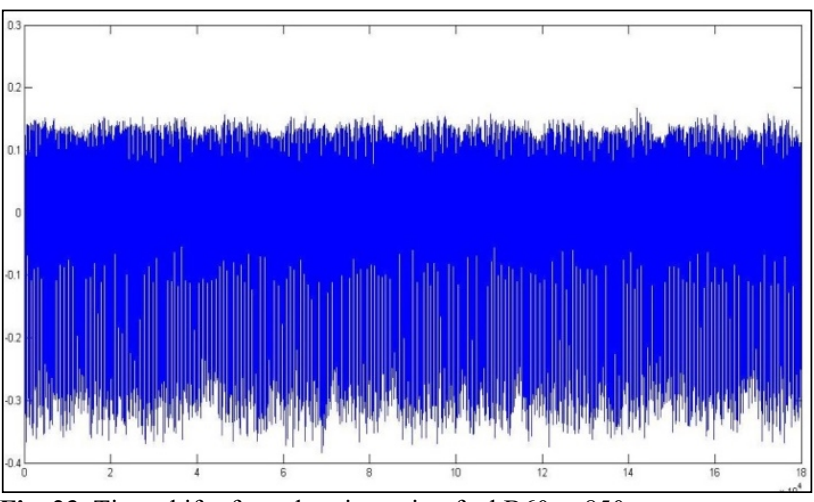

Fig. 23. Time shift of acceleration using fuel B60 at $850 \mathrm{rpm}$

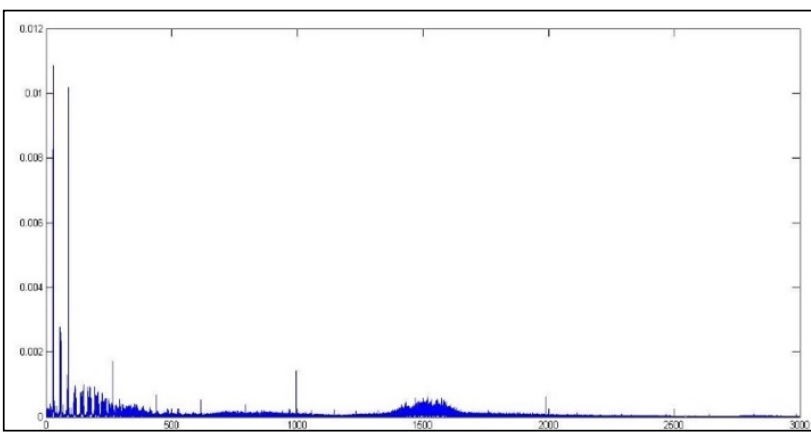

Fig. 24. Signal variation of accelerating action versus frequency using the FFT at $850 \mathrm{rpm}$

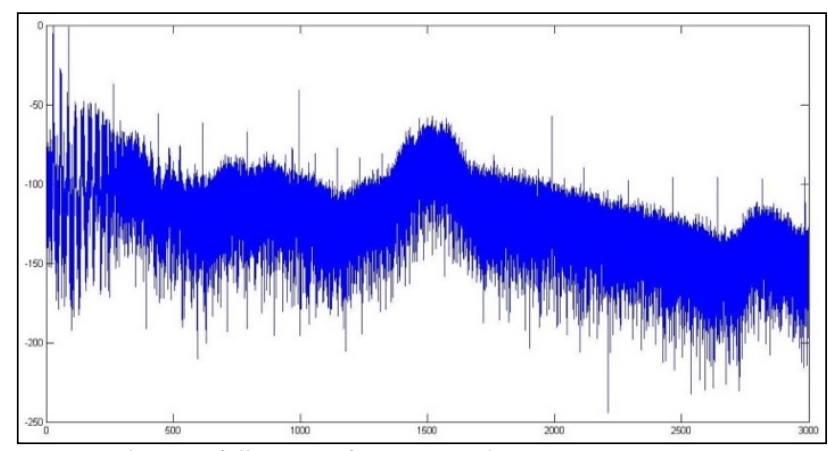

Fig. 25. Change of db versus frequency using B60 at $850 \mathrm{rpm}$

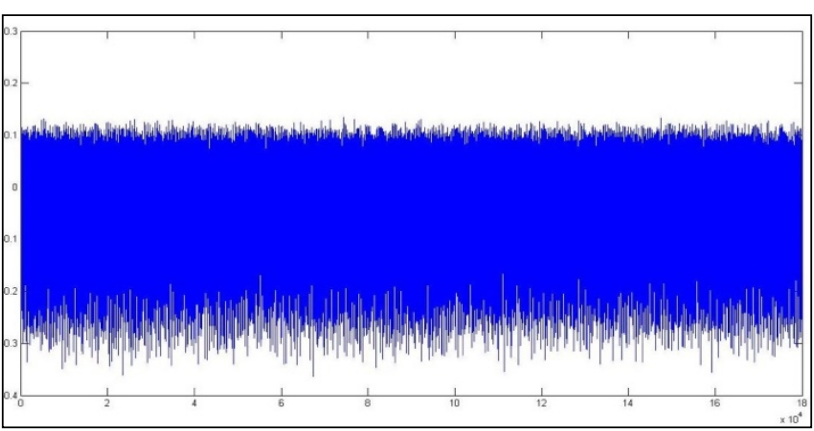

Fig. 26. Time shift of acceleration using fuel B60 at $1150 \mathrm{rpm}$

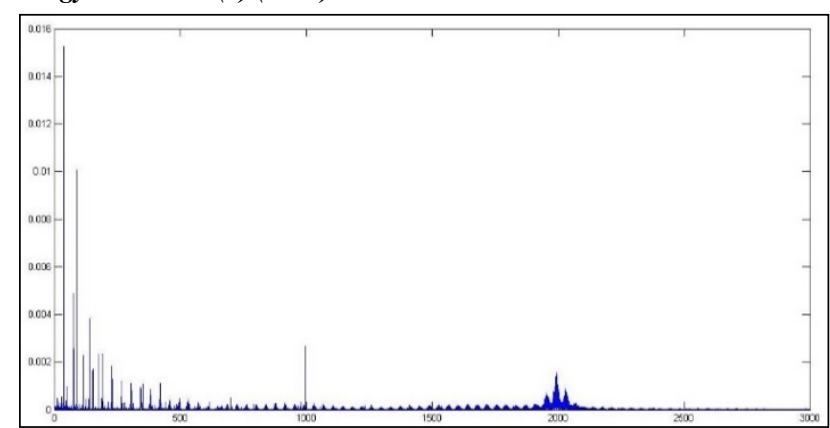

Fig. 27. Signal variation of accelerating action versus frequency using the FFT at $1150 \mathrm{rpm}$

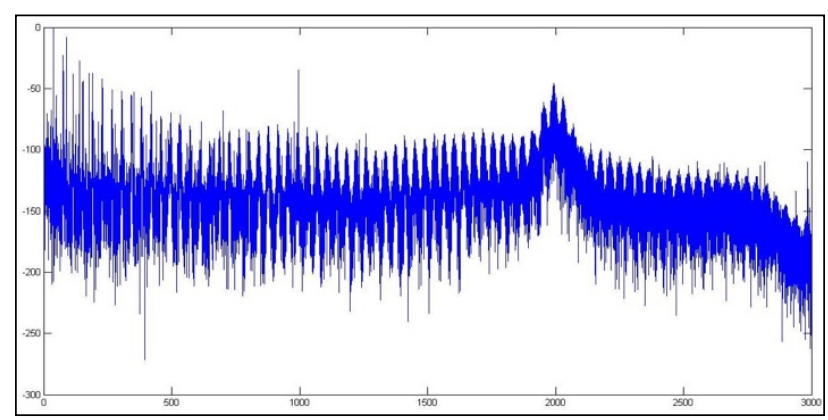

Fig. 28. Change of db versus frequency using B60 at $1150 \mathrm{rpm}$

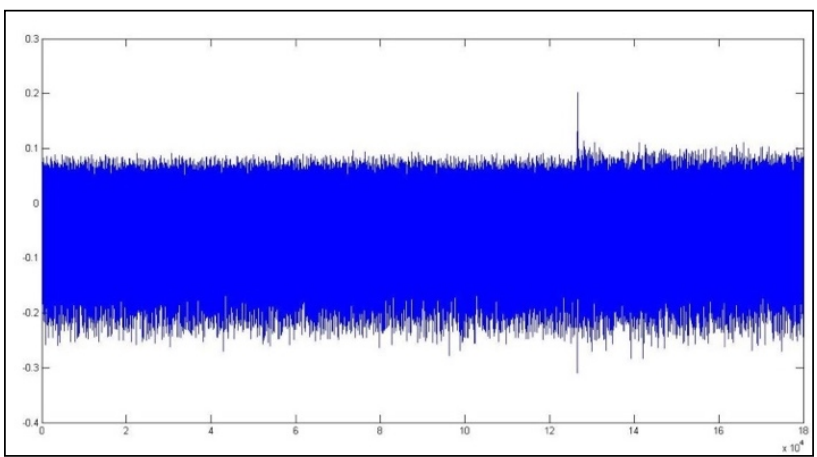

Fig. 29. Time shift of acceleration using fuel B60 at $2000 \mathrm{rpm}$

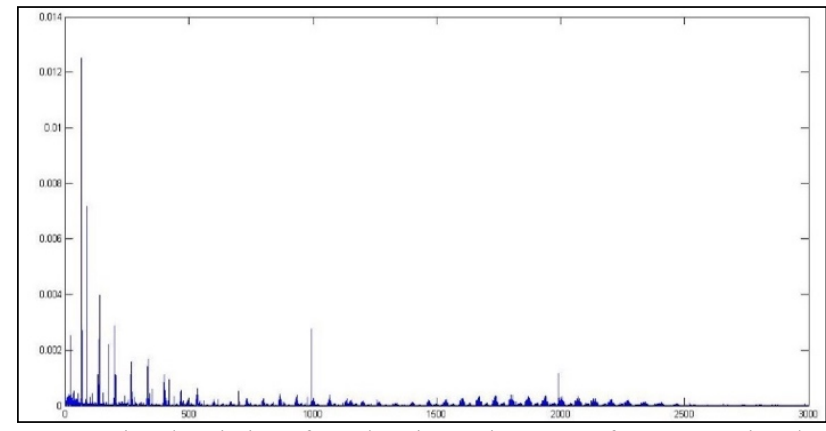

Fig. 30. Signal variation of accelerating action versus frequency using the FFT at $2000 \mathrm{rpm}$

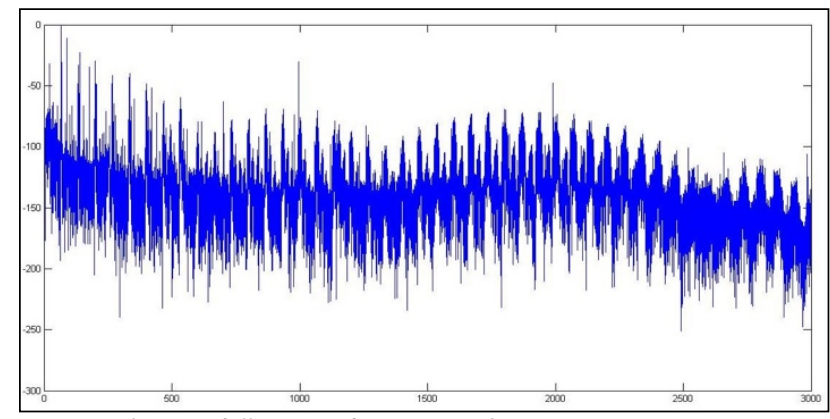

Fig. 31. Change of db versus frequency using B60 at $2000 \mathrm{rpm}$ 
G. D. Chaitidis, T. S. Karakatsanis, V. Kanakaris, K. M. Papachastas and I. Ch. Tsiafis/

Journal of Engineering Science and Technology Review 12 (5) (2019) 167 - 175

As shown in the below diagrams, the acceleration action value is displayed at lower levels than in the previous cases, which reinforces the previous finding regarding the power limitation produced by the engine. Figures $32-40$ show the evolution of phenomena for the 1150 and 2000 turns for the B80 mixture.

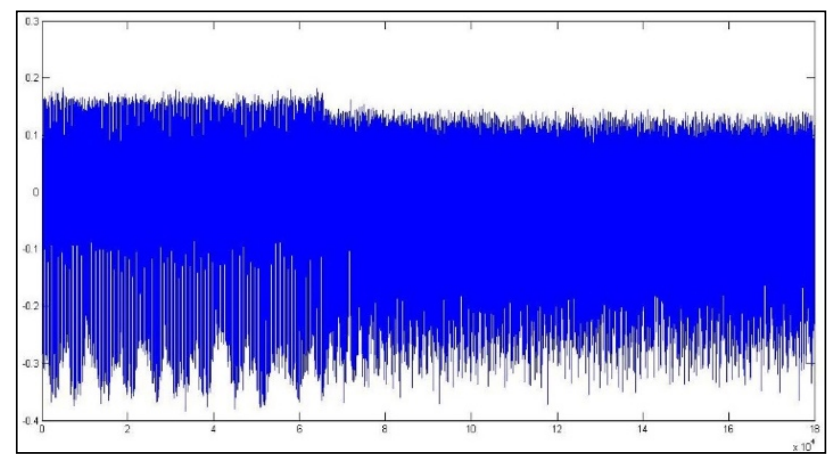

Fig. 32. Time shift of acceleration using fuel B80 at $850 \mathrm{rpm}$

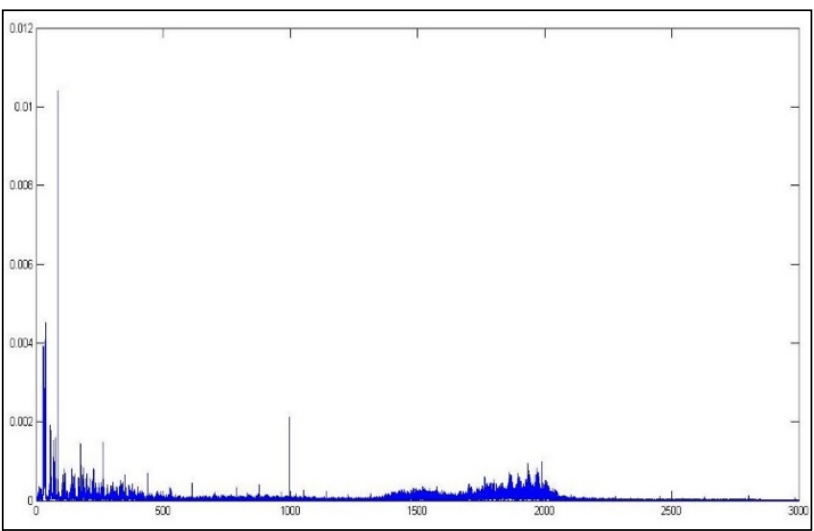

Fig. 33. Signal variation of accelerating action versus frequency using the FFT at $850 \mathrm{rpm}$

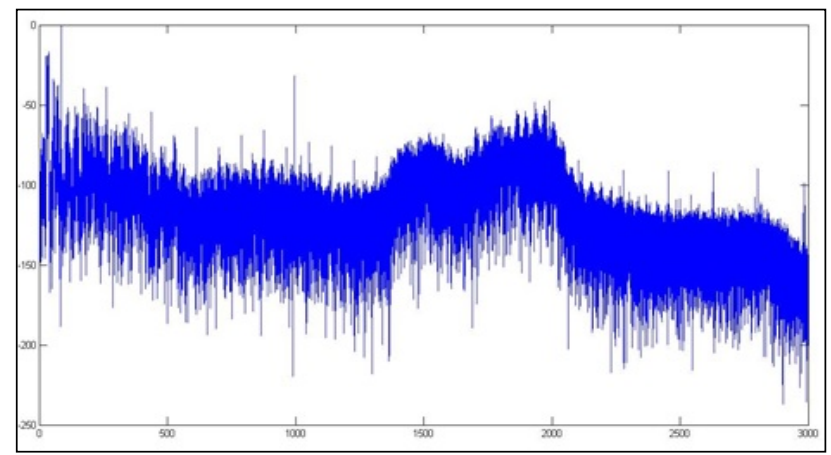

Fig. 34. Change of db versus frequency using B 80 at $850 \mathrm{rpm}$

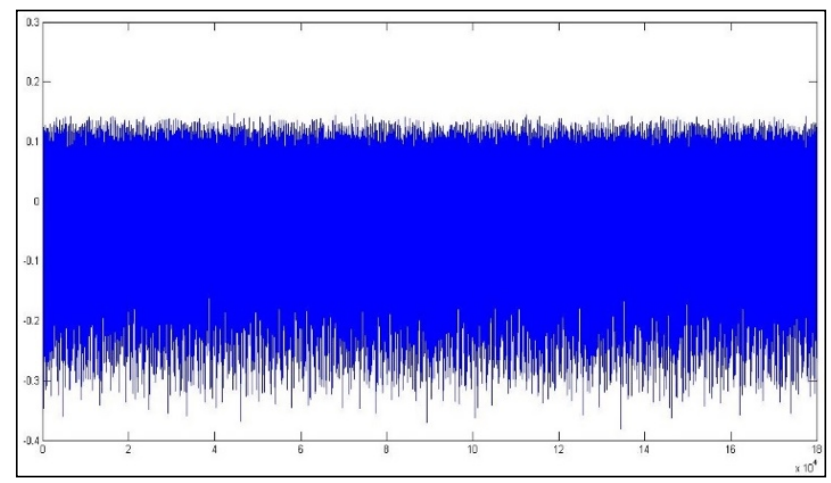

Fig. 35. Time shift of acceleration using fuel B80 at $1150 \mathrm{rpm}$

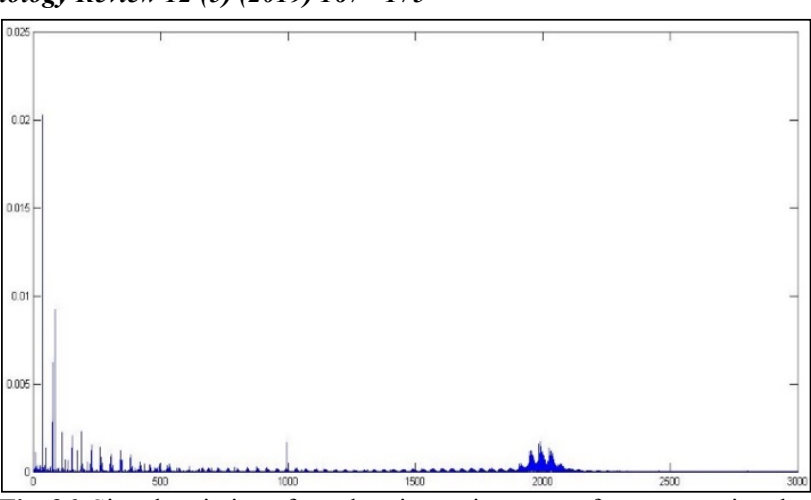

Fig. 36. Signal variation of accelerating action versus frequency using the FFT at $1150 \mathrm{rpm}$

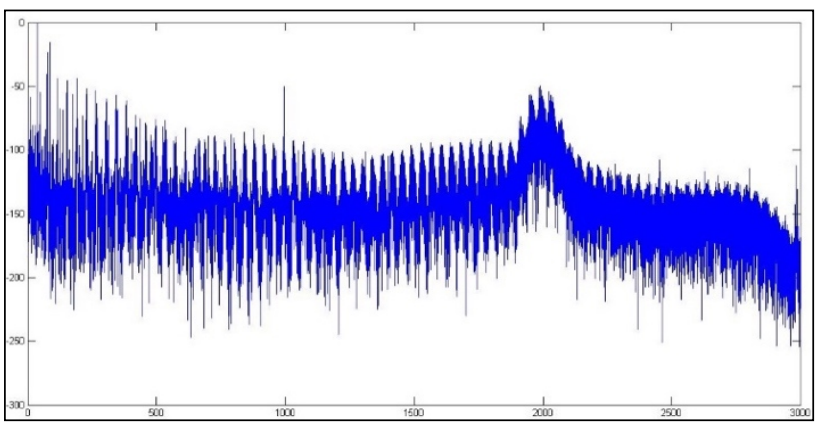

Fig. 37. Change of db versus frequency using B80 at $1150 \mathrm{rpm}$

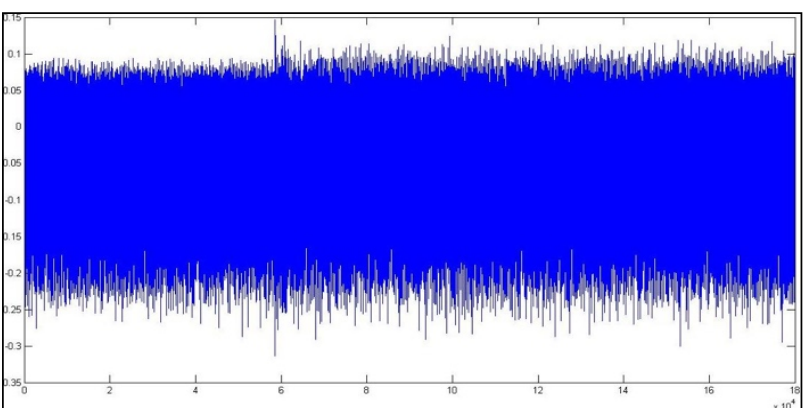

Fig. 38. Time shift of acceleration using fuel $\mathrm{B} 80$ at $2000 \mathrm{rpm}$

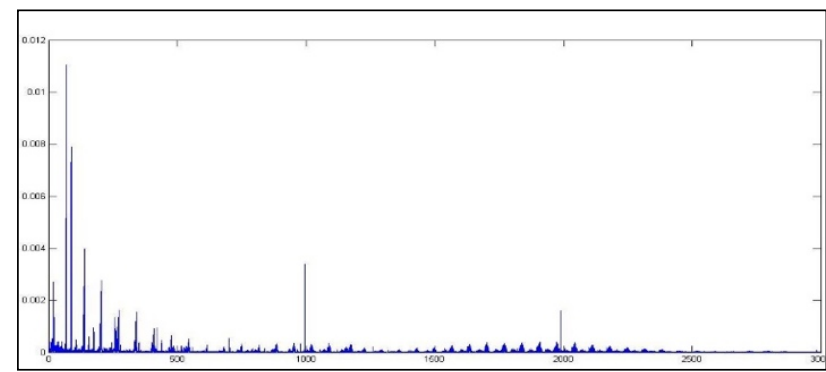

Fig. 39. Signal variation of accelerating action versus frequency using the FFT at $2000 \mathrm{rpm}$

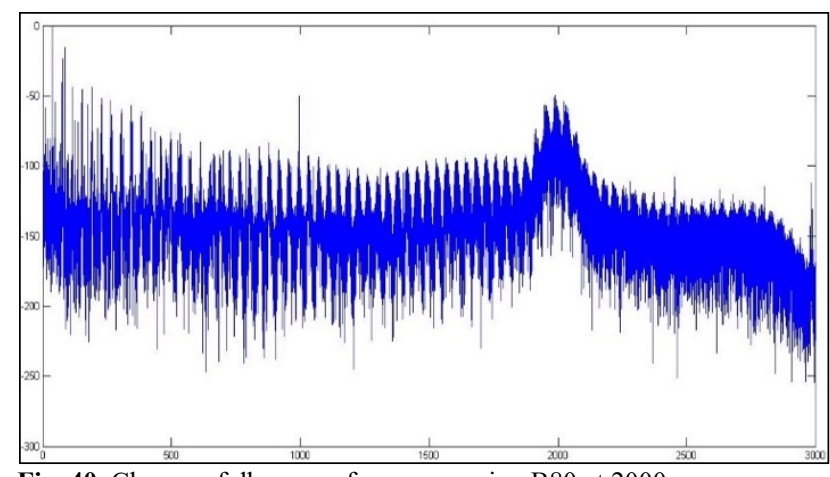

Fig. 40. Change of db versus frequency using B80 at 2000rpm 


\section{Conclusions}

According to the measurements, it appears that adding a significant percentage of biodiesel and specifically soybean oil to the mixture caused changes in engine behavior regarding vibrations. Specifically, the fuel mixture significantly affected the acceleration. Minimal reduction in acceleration observed by the use of mixtures of B20 and B40. Looking at the data from the graphs, the combustion of various blend fuels does not follow the same rules and depends on a number of parameters such as the proportions of the mixtures but most likely also the viscosity, lubrication properties, number of ketones and ignition point. Many researches showed that by increasing the percentage of biodiesel in fuel blends, the engine output power is reduced. This happened, as biodiesel has a higher viscosity and lower calorific value and in fuel mixtures, it can lead to incomplete combustion in the engine cylinder. In practice, the experiments from this study (Fig. 7,8,9) as the vibration values should do not have a steady downward trend as the percentage of biodiesel is reduced. Therefore, vibrations can also be affected by other factors such as the fuel cetane number. Possible factors that can affect vibration is also the level of oxygen in fuel mixtures as well as, the injection and spraying of the fuel. According to the diagram of the vibration action, increasing the biofuel content of the mixture, leads to reduced vibration energy (figure 41). Moreover, as the rpm increases, the vibration energy is reduced, So, it appears that the higher the soybean oil content it is, and higher the number of rpm on engine it is, faster the vibration energy is reduced.

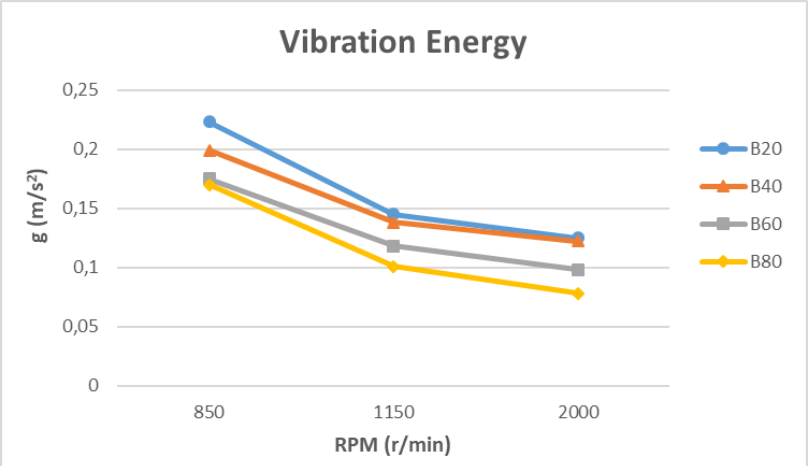

Fig. 41. Energy Vibration on four different mixtures

Generally in internal combustion engines, it is not customary to use this fuel for the time being. With demand for fuel increasing and oil showing price changes, the use of these fuels could be considered. For a better measurement of pressures and vibration extensions, a pressure sensor should be placed inside the cylinder. To do this, a hole in the engine body would have to be made a very difficult and costly procedure. The use of signal analysis in the frequency domain and analysis can lead to reliable conclusions about the state of combustion and the induced vibration.

This is an Open Access article distributed under the terms of the Creative Commons Attribution License

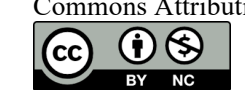

\section{References}

[1] Sidibé, S.S., Blin, J., Vaitilingom, G. and Azoumah, Y., 2010. Use of crude filtered vegetable oil as a fuel in diesel engines state of the art: Literature review. Renewable and Sustainable Energy Reviews, 14(9), pp.2748-2759.

[2] Rakopoulos, C.D., Antonopoulos, K.A., Rakopoulos, D.C., Hountalas, D.T. and Giakoumis, E.G., 2006. Comparative performance and emissions study of a direct injection diesel engine using blends of diesel fuel with vegetable oils or bio-diesels of various origins. Energy conversion and management, 47(18-19), pp.3272-3287.

[3] Haas, M.J., Scott, K.M., Alleman, T.L. and McCormick, R.L., 2001. Engine performance of biodiesel fuel prepared from soybean soapstock: a high quality renewable fuel produced from a waste feedstock. Energy \& Fuels, 15(5), pp.1207-1212.

[4] Fazal, M.A., Haseeb, A.S.M.A. and Masjuki, H.H., 2011. Biodiesel feasibility study: an evaluation of material compatibility; performance; emission and engine durability. Renewable and sustainable energy reviews, 15(2), pp.1314-1324.

[5] Nascimento, M.A., Lora, E.S., Correa, P.S., Andrade, R.V., Rendon, M.A., Venturini, O.J. and Ramirez, G.A., 2008. Biodiesel fuel in diesel micro-turbine engines: Modelling and experimental evaluation. Energy, 33(2), pp.233-240.

[6] Antoni, J., Daniere, J. and Guillet, F., 2002. Effective vibration analysis of ic engines using cyclostationarity. part ia methodology for condition monitoring. Journal of sound and vibration, 257(5), pp.815-837.

[7] Atmanli, A., Ileri, E., Yuksel, B. and Yilmaz, N., 2015. Extensive analyses of diesel-vegetable oil-n-butanol ternary blends in a diesel engine. Applied Energy, 145, pp.155-162.

[8] Dias, J.M., Alvim-Ferraz, M.C. and Almeida, M.F., 2009. Production of biodiesel from acid waste lard. Bioresource technology, 100(24), pp.6355-6361.

[9] Eckerle, W.A., Lyford-Pike, E.J., Stanton, D.W., LaPointe, L.A., Whitacre, S.D. and Wall, J.C., 2009. Effects of methyl ester biodiesel blends on NOx emissions. SAE International Journal of Fuels and Lubricants, 1(1), pp.102-118.
[10]Pehan, S., Jerman, M.S., Kegl, M. and Kegl, B., 2009. Biodiesel influence on tribology characteristics of a diesel engine. Fuel, 88(6), pp.970-979.

[11] Yaakob, Z., Mohammad, M., Alherbawi, M., Alam, Z. and Sopian, K., 2013. Overview of the production of biodiesel from waste cooking oil. Renewable and sustainable energy reviews, 18, pp.184193.

[12] Mueller, D., Ferrão, M., Marder, L., da Costa, A. and de Cássia de Souza Schneider, R., 2013. Fourier transform infrared spectroscopy (FTIR) and multivariate analysis for identification of different vegetable oils used in biodiesel production. Sensors, 13(4), pp.42584271.

[13] Selim, M.Y., 2001. Pressure-time characteristics in diesel engine fueled with natural gas. Renewable energy, 22(4), pp.473-489.

[14] Carlucci, A.P., Chiara, F.F. and Laforgia, D., 2006. Analysis of the relation between injection parameter variation and block vibration of an internal combustion diesel engine. Journal of sound and vibration, 295(1-2), pp.141-164.

[15] Du, X., Li, Z., Bi, F., Zhang, J., Wang, X. and Shao, K., 2012. Source separation of diesel engine vibration based on the empirical mode decomposition and independent component analysis. Chinese Journal of Mechanical Engineering, 25(3), pp.557-563.

[16]He, Q., 2013. Time-frequency manifold for nonlinear feature extraction in machinery fault diagnosis. Mechanical Systems and Signal Processing, 35(1-2), pp.200-218.

[17] Ettefagh, M.M., Sadeghi, M.H., Pirouzpanah, V. and Tash, H.A., 2008. Knock detection in spark ignition engines by vibration analysis of cylinder block: A parametric modeling approach. Mechanical Systems and Signal Processing, 22(6), pp.1495-1514.

[18] Guzzomi, A.L., Hesterman, D.C. and Stone, B.J., 2007. The effect of piston friction on the torsional natural frequency of a reciprocating engine. Mechanical Systems and Signal Processing, 21(7), pp.28332837.

[19] Sigmund, K.J., Shelley, S.J., Bauer, M. and Heitkamp, F., 2012, May. Analysis of vehicle vibration sources for automatic differentiation between gas and diesel piston engines. In Automatic Target Recognition XXII (Vol. 8391, p. 839109). International Society for Optics and Photonics.

[20]Chen, J., Randall, R.B. and Peeters, B., 2016. Advanced diagnostic system for piston slap faults in IC engines, based on the non- 
G. D. Chaitidis, T. S. Karakatsanis, V. Kanakaris, K. M. Papachastas and I. Ch. Tsiafis/

Journal of Engineering Science and Technology Review 12 (5) (2019) 167 - 175

stationary characteristics of the vibration signals. Mechanical Systems and signal processing, 75, pp.434-454.

[21]Ra, Y., Yun, J.E. and Reitz, R.D., 2009. Numerical parametric study of diesel engine operation with gasoline. Combustion Science and Technology, 181(2), pp.350-378.

[22] Taghizadeh A. Practical evaluation of vibration power tiller on user MSc thesis. Tarbiat Modarres University. Faculty of Agriculture. Agricultural Machinery Mechanic; 2005.

[23] Taghizadeh-Alisaraei, Ahmad, Barat Ghobadian, Teymour TavakoliHashjin, and Seyed Saeid Mohtasebi. "Vibration analysis of a diesel engine using biodiesel and petrodiesel fuel blends." fuel 102 (2012): 414-422.

[24]Hossain, A.B.M.S. and Al-Saif, A.M., 2010. Biodiesel fuel production from soybean oil waste as agricultural bio-resource. Australian journal of crop science, 4(7), p.538. 